\title{
Studi Kapasitas Dan Tingkat Pelayanan Jalan (Studi Kasus Jalan Mr. Muhammad Hasan Kota Banda Aceh)
}

\author{
${ }^{1}$ TetySriana, ${ }^{2}$ Kemalahayati \\ ${ }^{1}$ Program Studi Teknik Sipil, Fakultas Teknik, Universitas Abulyatama \\ 2Program Studi Teknik Sipil, Fakultas Teknik, Universitas Universitas Muhammadiyah Aceh \\ ${ }^{1}$ tetysriana_sipil@abulyatama.ac.id ${ }^{2}$ kemala.hayati@unmuha.ac.id
}

\begin{abstract}
Mr. Muhammad Hasan is street one of the entrance gates to Banda Aceh City. The condition of the road is in steady condition, with a two-lane, two-way type divided with a median of $1.5 \mathrm{~m}$ wide. The role of this road is very strategic, considering that if a tsunami occurs, this road is one of the community's escaped roads. The results of initial observations of this road are still in a comfortable condition to drive, but it is necessary to research the level of service to anticipate its role as an escape road. Based on that, we want to know how the level of service on Jalan Mr. Muhammad Hasan. The purpose of this study was to determine the level of service Jalan Mr. Muhammad Hasan using the 1997 MKJI method. Data were collected through a survey of traffic volume and speed for 3 (three) days, namely Thursday, Friday and Sunday. The duration of the survey is 07.00-18.00 with 8 (eight) surveyors. The traffic volume is multiplied by the number emp, so we get the amount of flow at peak hours in the morning, afternoon and evening. The result of recording speed in $\mathrm{m} / \mathrm{second}$ is converted to $\mathrm{km} / \mathrm{hour}$. Furthermore, the capacity of city roads, free flow speed and degree of saturation is calculated. Based on the value of capacity, speed and degree of saturation, the value of road service level is obtained. Based on the calculation results, the highest peak hours on observation day occurred in the afternoon, namely Thursday at $15.45-16.45$ (2144 p.m./hour), Friday at 16.15-17.15 (2295 p.m./hour) and Sunday at 17.00-18.00 as many as $1698 \mathrm{smp} /$ hour. hour. The capacity of the road on the three observation days was $6178 \mathrm{pcu} / \mathrm{hour}$ and the speed was $53.01 \mathrm{~km} / \mathrm{hour}$. The lowest degree of saturation occurred on Sunday afternoon at 0.18 and the highest occurred on Friday at 0.54 and overall it was still below 0.75 so there was no need for a scenario. The level of service in the morning and afternoon (Thursday, Friday, Sunday) still shows a value of A, while on Monday afternoon it becomes $\mathrm{C}$ and on Friday and Sunday it slightly decreases to B.
\end{abstract}

Keywords: Peak hour, capacity, degre of saturated, level of service

\begin{abstract}
Abstrak
Jalan Mr. Muhammad Hasan merupakan salah satu gerbang masuk ke Kota banda Aceh. Kondisi jalan dalam keaadaan mantap, dengan tipe dua lajur dua arah terbagi dengan median yang lebarnya 1,5 m.. Peran jalan ini begitu strategis, mengingat bila terjadi tsunami maka jalan ini merupakan salah satu escaped road masyarakat. Hasil observasi awal jalan ini masih dalam keadaan nyaman berkendaraan, tetapi perlu dilakukan penelitian tingkat pelayanan jalan untuk mengantisipasi perannya sebagai escape road. Berdasarkan itu ingin diketahui bagaimana tingkat pelayanan Jalan Mr. Muhammad Hasan. Tujuan penelitian ini adalah untuk mengetahui tingkat pelayanan Jalan Mr. Muhammad Hasan dengan memakai metode MKJI 1997. Pengambilan data dilakukan melalui survei volume dan kecepatan lalu lintas selama 3 (tiga hari) yaitu Kamis, Jumat dan Minggu. Durasi survei pukul 07.00-18.00 dengan 8 (delapan) surveyor. Volume lalu lintas dikalikan dengan angka emp, sehingga didapat besarnya arus pada jam puncak pagi, siang dan sore hari. Hasil pencatatan kecepatan dalam $\mathrm{m} / \mathrm{detik}$ dikonversi menjadi km/jam. Selanjutnya dihitung kapasitas ruas jalan kota, kecepatan arus bebas dan derajat kejenuhan. Berdasarkan nilai kapasitas, kecepatan dan derajat kejenuhan, maka didapatkan nilai tingkat pelayanan jalan. Berdasarkan hasil perhitungan Jam puncak tertinggi pada hari pengamtan terjadi pada sore hari, yaitu Kamis pukul15.45-16.45 (2144 smp/jam), jumat pada pukul 16.15-17.15 (2295 smp/jam) dan minggu pukul 17.00-18.00 sebanyak $1698 \mathrm{smp} / \mathrm{jam}$. Kapasitas ruas jalan pada ketiga hari pengamatan sebesar $6178 \mathrm{smp} / \mathrm{jam}$ dan kecepatan 53,01 km/jam. Derajat kejenuhan terendah terjadi pada Minggu siang yaitu 0,18 dan tertinggi terjadi pada hari jumat yaitu sebesar 0,54 dan secara keseluruhan masih di bawah 0,75 sehingga belum diperlukan adanya skenario. Tingkat pelayan jalan pagi dan siang (kamis,jumat, minggu) hari masih menunjukkan nilai $A$, sedangkan pada sore hari Senin menjadi $C$ dan pada hari jumat serta Minggu sedikit mengalami penurunan yaitu menjadi $B$.
\end{abstract}

Kata Kunci: Jam puncak, kapasitas, derajat kejenuhan, kecepatan, tingkat pelayanan https://doi.org/10.37598/tameh.v10i1.142

Diterima (Received): 29-06-2021 | Diperbaiki (Revised): 29-06-2021 | Diterima (Accepted): 30-06-2021 


\section{Pendahuluan}

Jalan Mr. Muhammad Hasan berawal dari Simpang Surabaya hingga tembus Jalan Lingkar Utara Selatan di Lampeuneurut sepanjang $4030 \mathrm{~m}$. Jalan ini merupakan salah satu akses pintu gerbang memasuki Kota Banda Aceh dengan tipe jalan 4 lajur 2 arah dengan median (4/2D) dan lebar lajur $2 \times 7,5$ $\mathrm{m}$. Alinemen jalan ini mendatar dengan 5 buah bukaan median. Letak jalan sangat strategis, kiri kanan merupakan pertokoan, kawasan kantor pemerintah dan Kawasan Terpadu Terminal Tipe A. Pada observasi awal secara umum jalan ini belum memiliki masalah yang berarti. Tetapi dengan semakin meningkatnya kegiatan kuliner di daerah ini, penambahan gedung perkantoran dan semakin besarnya angka kepemilikan kendaraan bermotor, maka dirasa perlu mengantisipasi sejak dini tentang lalu lintas dijalan ini. Kenyamanan lalulintas di

jalan ini perlu tetap dipertahankan mengingat jalan ini merupakan salah satu jalan keselamatan (escaped road) bagi masyarakat kota Banda Aceh bila terjadi gempa bumi dan tsunami. Sangat penting untuk mengetahui tingkat pelayanan jalan saat ini untukperkiraan tingkat kenyamann dimasa yang akan, agar escaped road dapat berfungsi dengan baik pada saat masyarakat membutuhkan. Untuk itu ingin diteliti tingkat pelayanan jalan dan tujuan dari penulisan ini adalah untuk mengetahui tingkat pelayanan Jalan Mr. Muhammad Hasan Kota Banda Aceh dengan menggunakan metode MKJI 1997. Beberapa penelitian tentang pelayanan jalan telah dilakukan oleh [8] di jalan kota Malang, [2] penelitian di jalan kota Pekanbaru, [6] Jalan di Cilegon dan [5] melakukan penelitian di Jakarta Selatan. Rata-rata penelitian ini menghasilkan tingkat pelayananC, $\mathrm{D}$ dan $\mathrm{E}$ serta $F$ yang menunjukkan bahwa gerakan kendaraan sudah mulai tidak lancar. Tingkat pelayanan yang semakin rendah (D,E $F$ ) mengakibatkan kemacetan yang akan merugikan semua pihak.

\section{Tinjauan Pustaka}

2.1 Transportasi dan Manajemen Infrastruktur

Template transportai merupakan salah satu unsur penting dalam menunjang https://doi.org/10.37598/tameh.v10i1.142 pembangunan. Salah satu sarana transportasi adalah jaringan jalan yang memiliki peran penting untuk memperlancar distribusi orang dan barang dari suatu tempat ke tempat yang lain [4]. Manajemen aset infrastruktur sangat diperlukan bagi infrastruktur jalan. Salah satu prinsip utama dalam melihat infrastruktur adalah bahwa infrastruktur diadakan untuk menjalan fungsi tertentu [9]. Fungsi jaringan jalan bisa dilihat dari aspek struktur jarinngan jalan. Dilihat dari sudut pandang struktur jaringan maka fungsi jaringan jalan adalah menghubungkan antar pusat kegiatan.

\subsection{Kapasitas Jalan Perkotaaan}

Kapasitas didefinisikan sebagai besarnyak volume lalulintas( arus) maksimum yang melalui suatu penampang melintang jalan atau yang melalui sutau titik yang dapat dipertahankan persatuan jam pada kondisi tertentu [1]. Persamaan dasar untuk menentukan besarnya kapasitas ruas jalan adalah sebagai berikut:

$\mathrm{C}=\mathrm{C}_{\mathrm{o}} \times \mathrm{F}_{\mathrm{cw}} \times \mathrm{FC}_{\mathrm{sp}} \times \mathrm{FC}_{\mathrm{sf}} \times \mathrm{FC}_{\mathrm{cs}}$

Dimana:

C = Kapasitas (smp/jam)

Co $=$ Kapasitas dasar (smp/jam)

$\mathrm{F}_{\mathrm{cw}}=$ Faktor penyesuaian lebar jalan

$\mathrm{FC}_{\mathrm{sp}}=$ Faktorpenyesuaian pemisah arah

$\mathrm{FC}_{\mathrm{sf}}=$ Faktor penyesuaian hambatan samping

$\mathrm{FC}_{\mathrm{cs}}=$ Faktor penyesuaian ukuran kota

\subsection{Derajat Kejenuhan (Degree of Saturated)}

Derajat kejenuhan (DS) didefinisikan sebagai rasio arus terhadap kapasitas jalan [1]. Nilai DS menunjukkan apakah segmen jalan tersebut mempunyai masalah terhadap kapasitas ruas jalan atau tidak, dengan persamaan sebagai berikut:

$D S=Q / C$

Keterangan:

DS = Derajat kejenuhan

$Q=$ Arus/volume lalu lintas

$\mathrm{C}=$ Kapasitas ruas jalan 


\subsection{Survei Arus dan Kapasitas Ruas}

Survei arus lalu lintas ditujukan untuk mendapatkan data jumlah kendaraan atau satuan mobil penumpang di suatu potongan melintang yang mewakili ruas tersebut pada periode waktu tertentu. Umumnya diklasifikasikan berdasarkan jenis kendaraan, arah arus dan terkadang posisi lajur. Data jumlah kendaraan yang terklasifikasi dibutuhkan untuk proses konversi menjadi satuan mobil penumpang. Pencacahan dikelompokkan per periode waktu tertentu misalnya 5menit dan 10 menit . Hal ini dimaksudkan agar fluktuasi arus lalu lintas sepanjang periode survei dapat dievaluasi [7]

\subsection{Satuan Mobil Penumpang (SMP)}

Satuan mobil penumpang adalah ukuran yang menunjukkan ruang jalan yang dipergunakan oleh suatu jenis kendaraan serta kemampuan manuver kendaraan tersebut. Atas dasar definisi di atas maka secara sefderhana nilai smpmobil penumpang (kendaraan ringan) adalah i, nilai smp sepeda motor $<1$ dan nilai smp kemdaraan berat adalah $>1$. Besarnya smp untuk tiap jenis kendaraan antara lain tergantung pada konfigurasi lajur jalan [7].

\subsection{Indek Tingkat Pelayanan (tergantung arus)}

Indek Tingkat Pelayanan (ITP) tergantung pada arus, hal ini berkaitan dengan kecepatan operasi atau fasilitas jalan, yang tergantung pada perbandingan anatararus terhadap kapasitas. Oleh karena itu tingkat pelayanan pada suatu jalan tergantung pada arus lalu lintas [10]. Besar. Besarn nilai ITP dapat dilihat pada Tabel 1 berikut ini:

\begin{tabular}{c|c|c|c}
\multicolumn{4}{c}{ Tabel 1. Indek Tingkat Pelayanan } \\
\hline $\begin{array}{c}\text { Tingkat } \\
\text { Pelayanan }\end{array}$ & $\begin{array}{c}\text { \% dari } \\
\text { Kecepatan } \\
\text { Bebas }\end{array}$ & $\begin{array}{c}\text { Tingkat } \\
\text { Kejenuhan } \\
\text { LaliLintas }\end{array}$ & Keterangan \\
\hline A & $\geq 90$ & $\leq 0,35$ & Lalu lintas bebas \\
\hline B & $\geq 70$ & $\leq 0,54$ & Stabil \\
\hline C & $\geq 50$ & $\leq 0,77$ & Masih Bata stabil \\
\hline D & $\geq 40$ & $\leq 0,93$ & Tidak Stabil \\
\hline E & $\geq 33$ & $\leq 1,0$ & Kadang Terhambat \\
\hline F & $<33$ & $>1$ & Dipaksakan/buruk \\
\hline
\end{tabular}

\section{Metode Penelitian}

Lokasi penelitian yang dipilih adalah di Kota Banda Aceh, yaitu pada ruas Dr. Mr. Muhammad Hasan. Jalan ini memiliki arus lalu lintas yang ramai, terutama pada jam-jam masuk dan keluar kerja atau sekolah/kuliah. Penelitian dilaksanakan pada hari Kamis, Jumat dan Minggu untuk mewakili hari sibuk dan untuk mendapatkan jam puncak. Waktu pencatatan dilakukan dari pagi sampai sore mulai jam 07.00-18.00 WIB tanpa henti dengan waktu pengamatan 15 menit.

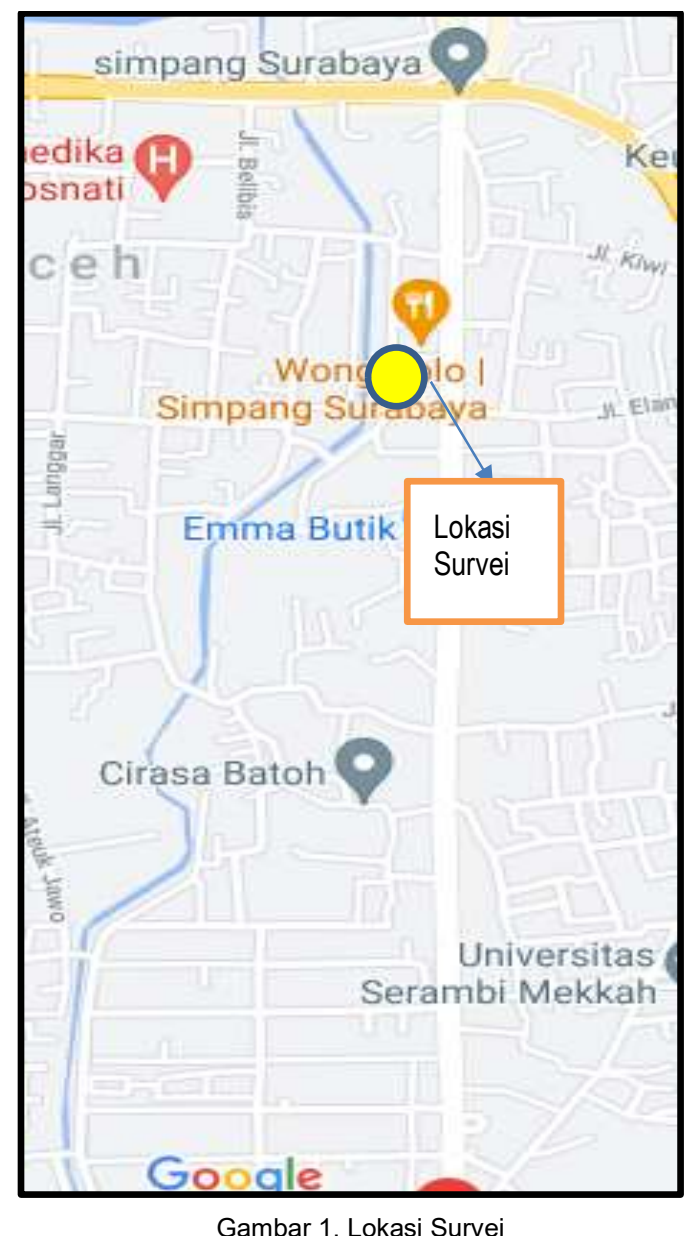

\subsection{Survei Pendahuluan}

Survei pendahuluan adalah survei sederhana yang dilakukan sebelum survei utama dengan tujuan:

1. Mengetahui kondisi lapangan;

2. Memilih metode survei yang paling baik untuk diterapkan sesuai kondisi lapangan; 
3. Menentukan lokasi surveyor untuk mengambil data primer di lapangan pada saat survei utama di lapangan.

Survei pendahuluan ini diharapkan dapat mendukung pelaksanaan kegiatan survei utama, sehingga diperoleh data hasil survei utama yang akurat. Dari hasil survei pendahuluan diperoleh foto lalu lintas kendaraan di Jalan Dr. Mr. Muhammad Hasan Kota Banda Aceh.

\subsection{Metode Pengumpulan Data}

Data yang akan diambil dalam survei utama ini terdiri dari 2 (dua) macam, yaitu:

a. Data primer

Data primer adalah data yang diperoleh dengan pengambilan data secara langsung di lapangan. Data primer dalam penelitian ini meliputi:

1. Data Volume Lalu lintas, Kecepatan dan Komposisi Lalu Lintas

Data volume lalulintas ruas jalan dilakukan dengan cara penghitungan manual (manual counting) pada satu titik pengamatan di daerah pada ruas Jalan Dr. Mr. Muhammad Hasan. Penghitungan dilakukan dalam periode 15 menitan pada pukul 07.00 sampai pukul 18.00 pada hari kerja hari Kamis, Jumat dan Minggu Kendaraan yang dihitung dibedakan dalam kendaraan berat, kendaraan ringan, sepeda motor, dan kendaraan tak bermotor berdasarkan metoda MKJI 1997.

2. Data Hambatan Samping.

Survei hambatan samping ini dilakukan dengan melihat apa saja kondisi hambatan samping (yang diamati berdasarkan kriteria baku MKJI 1997) dan di amati di sekitas pos pengamatan.

b. Data sekunder

Data sekunder adalah data jadi yang diperoleh dari instansi-instansi yang terkait, meliputi peta situasi ruas jalan dan persimpangan dengan ukuran-ukuran geometriknya dan ukuran kota (jumlah penduduk).

\subsection{Kecepatan Lalu Lintas}

Kecepatan setempat diperoleh dari haasil bagi antara panjang pias melewatinya. Untuk kedua https://doi.org/10.37598/tameh.v10i1.142 ruas jalan ditentukan masing-masing pias jalan sepanjang 60 meter. Pengamatan dengan lama waktu yang diperlukan untuk kecepatan setempat setiap interval waktu pengamatan 15 menit pada tiap lajur satu arah akan dirataratakan secara statistik yang disederhanakan untuk mendapatkan kecepatan setempat ratarata selama satu jam puncak pagi, siang dan sore.

\subsection{Kapasitas Jalan}

Besarnya kapasitas kedua ruas jalan dapat ditentukan dengan mengalikan nilai kapasitas dasar dengan factor penyesuaian lebar jalan, hambatan samping, pemisah arah dan ukuran kota.

\subsection{Derajat Kejenuhan}

Derajat kejenuhan adalah rasio arus terhadap kapasitas di gunakan sebagai faktor kunci dalam penentuan perilaku lalu lintas pada suatu simpang dan juga segmen jalan. Nilai derajat kejenuhan menunjukkan apakah segmen jalan akan mempunyai masalah kapasitas atau tidak.

Nilai derajat kejenuhan (DS) untuk masingmasing ruas jalan harus dihitung sehingga diketahui perbedaan nilai DS pada masingmasing ruas jalan yang dikanalisasi dan non kanalisasi. Untuk kinerja ruas jalan dan bagian jalinan tunggal, kapasitas actual (C) harus lebih besar dari arus lalu lintas yang terjadi $(Q)$. Dengan diketahui nilai kapasitas jalan (C) dan volume lalu lintas $(Q)$ maka dapat dihitung nilai derajat kejenuhan (DS). Nilai $D S=Q / C$ harus lebih kecil dari derajat kejenuhan normal yaitu 0,75 sedangkan untuk jalan tunggal derajat kejenuhan (DS) harus lebih kecil dari DS rencana yaitu 0,80 .

\subsection{Tingkat Pelayanan}

Tingkat pelayanan merupakan ukuran dari suatu ruas jalan yang dipenuhi nilai kapasitas jalan, derajat kejenuhan dan kecepatan pada masing-masing ruas jalan. Dari ukuran tersebut diatas maka dapat diketahui untuk masing-masing ruas jalan golongan tingkat pelayanan sesuai dengan yang ditetapkan. 


\section{Hasil dan Pembahasan}

Berdasarkan perhitungan didapat hasi Isebagai berikut:

\subsection{Jam Puncak}

Berdasarkan hasil perhitungan di dapat bahwa pada hari Senin jam puncak pagi terjadi pada pukul 07.15 - 08.15 dengan besarnya arus lalu lintas adalah 2037 smp/jam. Jam puncak siang terjadi pada pukul $13.45-14.45$ dengan besarnya arus 1997 smp/jam dan jam puncak sore terjadi pada pukul $15.45-16.45$ dengan besarnya arus $2144 \mathrm{smp} / \mathrm{jam}$.

Pada hari Jumat jam puncak pagi terjadi pada pukul $07.30-08.30$ dengan besarnya arus lalu lintas adalah $2196 \mathrm{smp} / \mathrm{jam}$. Jam puncak siang terjadi pada pukul 11.15 - 12.15 dengan besarnya arus $2194 \mathrm{smp} / \mathrm{jam}$ dan jam puncak sore terjadi pada pukul $16.15-17.15$ dengan besarnya arus $2295 \mathrm{smp} / \mathrm{jam}$.

Berikutnya pada hari Minggu/libur jam puncak pagi terjadi pada pukul 09.00 - 10.00 dengan besarnya arus lalu lintas adalah 1292 smp/jam. Jam puncak siang terjadi pada pukul 11.15 - 12.15 dengan besarnya arus 1110 smp/jam dan jam puncak sore terjadi pada pukul 17.00 - 18.88 dengan besarnya arus $1698 \mathrm{smp} / \mathrm{jam}$.

\subsection{Kapasitas Jalan}

Hasil perhitungan kapasitas ruas jalan didapat hasil yang sama pada untuk 3 (tiga) pengamatan, yaitu sebesar 6178 smp/jam. Untuk lebih jelasnya perhitngan kapasitas jalan dapat dilihat pada Tabel 2 sebagai berikut:

Tabel 2. Kapasitas Ruas Jalan

\begin{tabular}{l|ll|l|c}
\hline \multirow{2}{*}{ Hari } & \multicolumn{3}{c|}{ Periode } & $\begin{array}{c}\text { Kapasitas } \\
\text { jalan } \\
\text { (smp/jam) }\end{array}$ \\
\hline Kamis & Jam & Puncak & $07: 15-$ & 6178 \\
& Pagi & & $08: 15$ & \\
& Jam & Puncak & $13: 45-$ & 6178 \\
& Siang & & $14: 45$ & \\
& Jam & Puncak & $15: 45-$ & 6178 \\
& Sore & & $16: 45$ & 6178 \\
& Jam & Puncak & $07: 30-$ & \\
& Pagi & & $08: 30$ & 6178 \\
& Jam & Puncak & $11: 15-$ & \\
& Siang & & $12: 15$ & \\
& Jam & Puncak & $16: 15-$ & \\
\hline
\end{tabular}

\begin{tabular}{l|ll|l|l}
\hline & \multicolumn{2}{|l|}{ Sore } & $17: 15$ & 6178 \\
\hline Minggu & Jam Puncak & $09: 00-$ & 6178 \\
& Pagi & $10: 00$ & \\
& Jam Puncak & $12: 45-$ & 6178 \\
& Siang & $13: 45$ & \\
& Jam Puncak & $17: 00-$ & 6178 \\
& Sore & $18: 00$ & 6 \\
\hline
\end{tabular}

\subsection{Kecepatan arus Bebas}

Kecepatan arus bebas hasil pengamatan adalah sama yaitu $53,01 \mathrm{~km} / \mathrm{jam}$ selama tiga hari pengamatan. Untuk lebih jelasnya dapat dilihat pada Tabel 3 berikut Ini:

Tabel.3 Kecepatan Arus Bebas Kendaraan

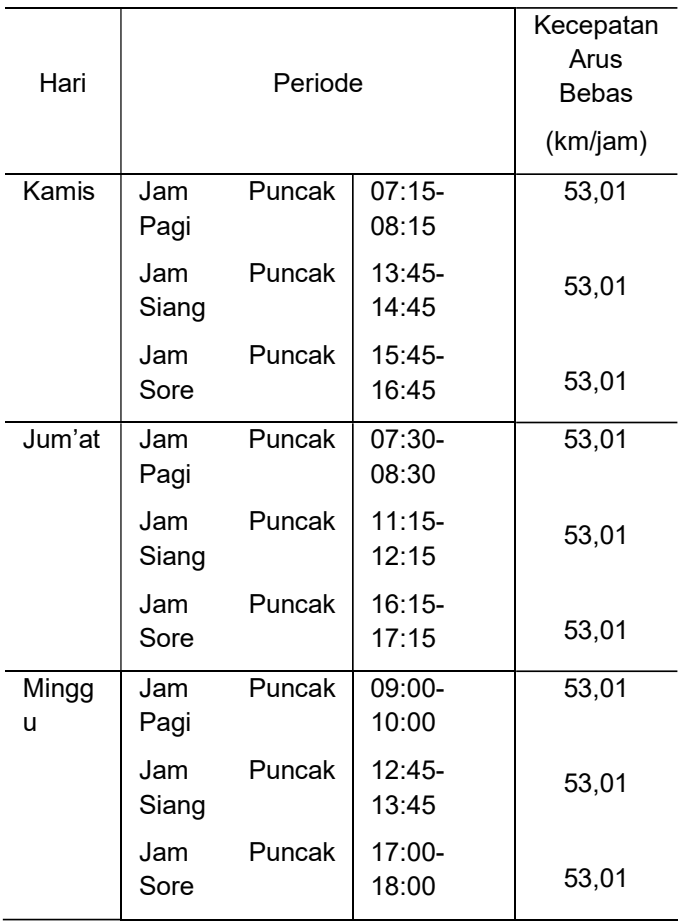

4.3 Derajat Kejenuhan

Berdasarkan hasil perhitungan didapat didapat besarnya derajat kejenuhan pada hari senin pagi adalah sebesar 0,33 , pada siang hari hampr sama yaitu 0,32 . Terjadi peningkatan angkat derajat kejenuhan sebanyak $62 \%$ sehingga pada sore hari terjadi derajat kejenuhan sebesar 0,51 .

Hasil perhitungan dearajat kejenuhan pada hari jumat pada pagi dan siang hari adalah sebesar 0,35 dan 0,36.Pada sore hari terjadi peningkatan derajat kejenuhan sebanyak $50 \%$ sehingga menjadi 0,54 . 
Adapun hasil perhitungan dearajat kejenuhan pada hari Senin pada pagi dan siang hari adalah sebesar 0,21 dan 0,18. Pada sore hari terjadi peningkatan derajat kejenuhan menjadi 0,41 .

Bila diamati lebih lanjut didapatkan bahwa derajat kejenuhan pada tiap hari pengamatan mengalami peningkatan padasore hari, baikpada hari Senin, Jumat maupun pada hari Minggu. Derat kejenuhan tertinggi terjadi pada Hari Jumat sore dan terendah terjadi pada siang Minggu. Rendahnya derajat kejenuhan di hari siang ini karena hari ini merupakan hari libur dan jalan ini bukan merukan jalan akses menuju tempat wisata.

Selengkapnya hasil perhitungan derajat kejenuhan disampaikan pada Tabel 4 beriku ini:

Tabel 4. Derajat Kejenuhan

\begin{tabular}{|c|c|c|c|c|}
\hline Hari & \multicolumn{3}{|c|}{ Periode } & $\begin{array}{c}\text { Derajat } \\
\text { Kejenuha } \\
\mathrm{m}\end{array}$ \\
\hline Kamis & $\begin{array}{l}\text { Jam } \\
\text { Pagi } \\
\text { Jam } \\
\text { Siang } \\
\text { Jam } \\
\text { Sore }\end{array}$ & $\begin{array}{l}\text { Puncak } \\
\text { Puncak } \\
\text { Puncak }\end{array}$ & $\begin{array}{l}07: 15- \\
08: 15 \\
13: 45- \\
14: 45 \\
15: 45- \\
16: 45\end{array}$ & $\begin{array}{l}0,33 \\
0,32 \\
0,52\end{array}$ \\
\hline Jum'at & $\begin{array}{l}\text { Jam } \\
\text { Pagi } \\
\text { Jam } \\
\text { Siang } \\
\text { Jam } \\
\text { Sore } \\
\end{array}$ & $\begin{array}{l}\text { Puncak } \\
\text { Puncak } \\
\text { Puncak }\end{array}$ & $\begin{array}{l}07: 30- \\
08: 30 \\
11: 15- \\
12: 15 \\
16: 15- \\
17: 15 \\
\end{array}$ & $\begin{array}{l}0,35 \\
0,36 \\
0,54\end{array}$ \\
\hline Minggu & $\begin{array}{l}\text { Jam } \\
\text { Pagi } \\
\text { Jam } \\
\text { Siang } \\
\text { Jam } \\
\text { Sore }\end{array}$ & $\begin{array}{l}\text { Puncak } \\
\text { Puncak } \\
\text { Puncak }\end{array}$ & $\begin{array}{l}09: 00- \\
10: 00 \\
12: 45- \\
13: 45 \\
17: 00- \\
18: 00\end{array}$ & $\begin{array}{l}0,21 \\
0,18 \\
0,41\end{array}$ \\
\hline
\end{tabular}

\subsection{Tingkat Pelayanan Jalan}

Tingkat pelayanan jalan pada hari senin dipagi hari masih sangat bagus dengan tingkat pelayanan adalah A. Artinya arus lalu lintas dapat bergerak dengan bebas dan lancar. Pada sore hari terjadi penurunan tingkat pelayanan menjadi $B$ dimana arus masih dianggap stabil.

Pada Hari jumat dipagi dan siang hari tingkat pelayanan adalah $\mathrm{A}$ dan sedikit berubah menjadi B yang artinya arus lalulintas bebas lancar.

Pada hari Minggu pagi dan siang, tingkat pelayanan jalanadalah A dimana artinya arus lalulintas adalah arus bebas yang sangat lancar.Pada sore hari tingkat pelayanan jalan adalah $b$ dimana masih dianggaparus bebas lalu lintas untuk jalan dalam kota.

Secara keseluruhan dar pengamatan diketahui bahwa tingkat pelayanan jalan Mr. Mihammada Hasan rata-ra adalah A yang artinya arus lalu lintas masih dengan leluasi dapat bebas bergerak.

Tabel 5. Tingkat Pelayanan

\begin{tabular}{|c|c|c|c|c|}
\hline Hari & \multicolumn{3}{|c|}{ Periode } & $\begin{array}{c}\text { Tingkat } \\
\text { Pelayanan }\end{array}$ \\
\hline Kamis & $\begin{array}{l}\text { Jam } \\
\text { Pagi } \\
\text { Jam } \\
\text { Siang } \\
\text { Jam } \\
\text { Sore }\end{array}$ & $\begin{array}{l}\text { Puncak } \\
\text { Puncak } \\
\text { Puncak }\end{array}$ & $\begin{array}{l}07: 15- \\
08: 15 \\
13: 45- \\
14: 45 \\
15: 45- \\
16: 45\end{array}$ & $\begin{array}{l}\text { A } \\
\text { A } \\
\text { C }\end{array}$ \\
\hline Jum'at & $\begin{array}{l}\text { Jam } \\
\text { Pagi } \\
\text { Jam } \\
\text { Siang } \\
\text { Jam } \\
\text { Sore }\end{array}$ & $\begin{array}{l}\text { Puncak } \\
\text { Puncak } \\
\text { Puncak }\end{array}$ & $\begin{array}{l}07: 30- \\
08: 30 \\
11: 15- \\
12: 15 \\
16: 15- \\
17: 15\end{array}$ & $\begin{array}{l}\mathrm{A} \\
\mathrm{A}\end{array}$ \\
\hline Minggu & $\begin{array}{l}\text { Jam } \\
\text { Pagi } \\
\text { Jam } \\
\text { Siang } \\
\text { Jam } \\
\text { Sore }\end{array}$ & $\begin{array}{l}\text { Puncak } \\
\text { Puncak } \\
\text { Puncak }\end{array}$ & $\begin{array}{l}09: 00- \\
10: 00 \\
12: 45- \\
13: 45 \\
17: 00- \\
18: 00\end{array}$ & $\begin{array}{l}\text { A } \\
\text { A } \\
\text { B }\end{array}$ \\
\hline
\end{tabular}

\subsection{Pembahasan}

Dari hasil perhitungan didapat derajat kejenuhan ruas Jalan Dr. Mr. Muhammad Hasan masih di bawah 0,75 yang menurut MKJI 1997 dianggap dalam kondisi baik dengan arus lalu lintas yang masih lancar. sedangkan kapasitas aktualnya adalah 6178 smp/jam.

Dari hasil survei kecepatan arus bebas untuk tiap jam puncak pagi, siang dan sore hari masih dibawah $57 \mathrm{~km} / \mathrm{jam}$. Hal ini berarti kecepatan kendaraan untuk semua jam sibuk pada hari survei masih di bawah kecepatan arus bebas dasar kendaraan yang menurut MKJI 1997 adalah 57 km/jam. 
Dari hasil perhitungan kecepatan arus bebas, kapasitas dan derajat kejenuhan didapat tingkat pelayanan Jalan Dr. Mr. Muhammad hasan masih dalam kondisi bagus dengan tidak adanya tingkat pelayanan $\mathrm{D}, \mathrm{E}$ dan $\mathrm{F}$.

Bila dibandingkan dengan penelitian oleh [8] yang melakukan penelitian dikota Malang pada Jalan Sunan Kalijda mendapatkan tingkat pelayanan jalan pada nilai $F$, adapun [2] yang melakukan penelitian di Jalan Sudirman Kota Pekanbaru menghasil data tingkat pelayanan jalan pada nilai $D$ (arus mulai tidak stabil) dan hasil penelitian [6] yang mengadakan penelitian di jalan Ciledug Raya Jakarta selatan menghasilkan Tingkat Pelayanan Jalan dengan nilai E. [3] meneliti tentang kapasitas ruas jalan Sam Ratulangi di Kota Menado dan mendapatkan hasil derajat kejenuham sebesar 0,72 , kurang dari 0,75 artinya lalu lintas di jalan tersebut masih stabil.

\section{Kesimpulan}

Berdasarkan dari hasil penelitian dan analisis data yang telah dilakukan maka dapat diambil beberapa kesimpulan yaitu sebagai berikut:

1. Dari hasil perhitungan didapat derajat kejenuhan ruas Jalan Dr. Mr. Muhammad Hasan masih di bawah 0,75 yang menurut MKJI 1997 dianggap dalam kondisi baik dengan arus lalu lintas yang masih lancar. sedangkan kapasitas aktualnya adalah 6178 smp/jam.

2. Dari hasil survei kecepatan arus bebas untuk tiap jam puncak pagi, siang dan sore hari masih dibawah $57 \mathrm{~km} / \mathrm{jam}$. Hal ini berarti kecepatan kendaraan untuk semua jam sibuk pada hari survei masih di bawah kecepatan arus bebas dasar kendaraan yang menurut MKJI 1997 adalah $57 \mathrm{~km} / \mathrm{jam}$.

3. Dari hasil perhitungan kecepatan arus bebas, kapasitas dan derajat kejenuhan didapat tingkat pelayanan Jalan Dr. Mr. Muhammad hasan masih dalam kondisi bagus dengan tidak adanya tingkat pelayanan $\mathrm{D}, \mathrm{E}$ dan $\mathrm{F}$.

4. Belum diperlukan manajemen lalu lintas (skenario) untuk jalan Dr. Mr. Muhammad
Hasan karena derajat kejenuhannya masih di bawah 0,75

\section{Daftar Pustaka}

[1] Anonymous, 1997, Manual Kapasitas jalan Indonesia(MKJI), Departemen Pekerjaan Umum, Jakarta.

[2] Khairulnas, et al, 2018, Analida Derajat Kejenuhan dan Tingkat Pelayanan Jalan Sudirman Kota Pekan Baru, Jurnal Teknik, 12(2),pp 148-154

[3] Lalenoh, R. H., Sendow, T.K. \& Jansen, F., 2015 AnalisaKapasitas Ruas jalan Sam Ratulangi dengan Metode MKJI dan PKJI 2014, Jurnal Sipil Statik, 3(11), pp. 737-746

[4] Mutiawati, C., Suprayitno, H., 2018, Tinjauan Awal Struktur Jaringan Jalan di Kota Banda Aceh, Jurna Manajemen Aset Infrastruktur dan Fasilitas, 2 (2), pp 40-52.

[5] Pradana, M.F., Bethary, R.T. \& Permana, T. E, 2016, Analisis Kinerja Tiga Ruas Jalan Utama Kota Cilegon, Jurnal Fondasi, 5(1), pp, 46-56.

[6] Prasetyo, H. E dan Trijeti, 2019, Seminar Nasional Sains dan Teknologi, Fakultas Teknik Universitas Muhammadiyah Jakarta

[7] Putranto, L.S, 2016, Rekayasa laluLintas, Indeks, Bandung

[8] Suhudi \& Tenabolo, A., 2017, Analisis Tingkat Pelayanan Jalan Sunan Kalijaga Kelurahan Dinoyo Kecamatan Lowokwaru Kota Malang, Jurnal Reka Buana, 2(1), pp, 47-55

[9] Suprayitno, H., \& Soemitro, R.A.A., 2018, Preliminary Reflexion on Basic Principleof Infrastructure Asset Management,Jurnalmanajemen Aset Infrastruktur dan Fasilitas, 2(1), pp.1-9.

[10]Tamin, O.Z, 2008, Perencanaa, Pemodelan dan Rekayasa Transportasi, Penertbi ITB, Bandung.. 